\title{
10
}

\section{Structuring Complex Cooperative Learning Activities in 50-Minute Classes}

\author{
Barbara J. Millis \\ University of Nevada-Reno
}

Given the power of learning-centered teaching, faculty can be coached to structure cooperative activities wisely and well, even within 50-minute class periods where there is a perception that complex group work is difficult. In addition to giving some basic advice on team formation and classroom management, this chapter provides examples of five complex cooperative learning structures-Jigsaw, Send-a-Problem, Cooperative Debates, Guided Reciprocal Peer Questioning, and Bingo-that can be conducted within 50-minute classes. The specific literature-based examples are complemented by examples in a variety of other disciplines, making them seem donble to more faculty.

\begin{abstract}
A s Bob Dylan sang so hauntingly in the 1960s, "The Times They Are AA Changin." Even in academia, where change is notoriously slow, faculty members are becoming increasingly aware, particularly with the broadening pool of incoming students, that business as usual will not result in significant learning gains. Barr and Tagg's (1995) influential Change magazine article, "From Teaching to Learning-A New Paradigm for Undergraduate Education," started a healthy movement toward rethinking the nature of teaching and learning. Subsequent books such as Weimer's (2002) Learner-Centered Teaching and Fink's (2003) Creating Significant Learning Experiences, as well as numerous articles, provided useful models and convincing research. Bransford, Brown, and Cocking's (2000) How People Learn made it difficult for even the most lecture-committed faculty member to ignore research with
\end{abstract}


clear implications for a more learning-centered basis of teaching. In fact, Finkel (2000) concludes, "Educational research over the past twenty-five years has established beyond a doubt a simple fact: What is transmitted to students through lecturing is simply not retained for any significant length of time" (p. 3).

Execution, however, remains a key issue for faculty developers and the faculty they support. Even faculty committed philosophically to the new paradigms often lack the know-how to successfully adapt teaching techniques and classroom management practices that can lead to more learning-oriented approaches, particularly in content-driven courses that meet only during 50minute class periods.

Faculty, however, can learn to use learning-centered approaches-particularly group work - if they can adopt a philosophical framework that allows for flexibility in the specific techniques employed.

Cooperative learning can provide a philosophical framework with clearly defined tenets, such as individual accountability (no undifferentiated "group grades" or social loafing) and positive interdependence (students have vested reasons to work together), that faculty can combine with virtually any other known pedagogy. Cases, for example, can be adapted to a cooperative format (Millis, 1994). Approaches such as the double entry journal, popularized by the writing across the curriculum movement, can be modified to include peer sharing and coaching as students read and discuss one another's products rather than watching them stuffed into a teacher's briefcase. Cooperative learning philosophies and practices also mesh beautifully with the research on how people learn and deep learning (Millis, 2002). Classroom assessment, problem-based learning, and academic games can all be enhanced through a cooperative approach. Technology and cooperative learning are natural partners, thanks to email, web-based teaching, and course management packages such as Blackboard or WebCT. Not surprisingly, virtual team performance requires many of the attributes of well-conducted classroom cooperative learning: attention to planning, executing, rewarding the tasks, and care in structuring individual accountability and mutual interdependence.

For faculty fearful of losing control if they relinquish the podium, cooperative learning components that focus on classroom management can be reassuring. Group processing, for example, provides approaches used by both students and faculty to help groups function well. Attention to group-based social skills such as leadership and group facilitation offer concrete ways to structure class experiences. 


\section{Team Formation and Classroom Management}

If faculty do not normally use group work in their classes, the faculty developer needs to coach them in effective team formation. Teachers should select the teams based on criteria suitable for the assignment, aiming for heterogeneity on as many levels as possible. In an adult education children's literature class, for example, teams might deliberately contain an English major (for content knowledge), a male (for gender balance), and a person with children (for "real-world" experience). Streuling (2004) purposefully distributes students with poor attitudes toward group work among the various teams to "defuse" (p. 136) their impact.

If purposeful selection is unnecessary or too time consuming, then random selection is the next option. Encourage faculty not to let students self-select their own team members because they usually select friends who look like and think like themselves and who often fall into traditional roles. Student self-selection is the number one reason teams fail. In one study, $155 \mathrm{stu}$ dents surveyed claimed in a 2:1 ratio that their worst group work experiences were with self-formed groups and their best ones were with instructorformed groups (Feichtner \& Davis, 1984-85). Other studies in the cooperative learning literature generally support this finding. If groups or teams are to be used over the course of a semester, then it is important to keep them together long enough to go through the expected group dynamic process. Tuckman (1965) and Tuckman and Jensen (1977) have identified these phases as forming, storming, norming, and performing (later versions of Tuckman's work refer to adjourning). Stein and Hurd (2000) remind us that working in teams is a developmental process that is aided by "an atmosphere of openness and reason" and by clearly defined "goals, procedures, and expectations" ( $p$. 20). Weimer's (2002) work on learner-centered teaching also emphasizes the importance of a developmental approach that moves students from "dependent, passive, often not confident ... to autonomous, motivated, responsible, empowered learner[s]" (p. 167).

Felder and Brent (1994) recommend that faculty forming teams should "avoid groups in which women and minority students are outnumbered." They argue against forming teams with one woman and two or three men, applying the same rule to minorities. Having taught for nine years at a service academy where women and minorities typically have strong voices, I usually ask the students in question how they feel about this issue.

Because roles are critically important in many activities, I typically form groups of four and have students distribute playing cards among team members. Thus, each team (aces, twos, threes, fours) consists of four members 
with the four suits, making it easy to assign roles or tasks when necessary (Millis \& Cottell, 1998).

\section{The Transition to More Sophisticated Learning-Centered Approaches}

As faculty developers, we can coach faculty in these classroom management approaches and watch them successfully try, even in large classes, wellknown, relatively simple cooperative approaches such as think-pair-share (Lyman, 1981). We can even exult in their adaptation and skillful use of socalled clickers (classroom response systems). But the transformation toward learning-centered teaching often remains stagnant at this point, particularly in 50-minute classes. Without adequate coaching to provide models and instill confidence, faculty rarely use more complex cooperative approaches, particularly in 50-minute class periods where the tacit assumption appears to be that there is insufficient time. Nothing, however, is further from the truth.

\section{Specific Examples of Complex Cooperative Learning Approaches Used in 50-Minute Classes}

This chapter will briefly describe how to sequence complex cooperative learning activities in 50-minute classes using five examples from a literature course that can be adapted to a range of other disciplines. Suggestions for adaptations follow the literature-based explanation. The cooperative learning examples include 1) Jigsaw based on homework on literature characters completed using a graphic organizer, 2) Send-a-Problem based on open-ended literature questions (e.g., Why does Hamlet treat Ophelia as he does?), 3) Cooperative Debate based on four teams focused on two questions (Pro/Con: Should Antigone have buried her brother? and Pro/Con: Should Creon be impeached for poor leadership?), 4) Guided Reciprocal Peer Questioning (structured group work based on Allison King's Question Stems), and 5) Bingo, a game used as a review for exams.

\section{Jigsaw}

Jigsaw is particularly useful for problem-solving activities that require students to confront complex, challenging topics involving multiple pieces of information necessary for final, overall mastery. In this activity, each member of a cooperative learning team assumes responsibility for a specific part of a problem. 
They are responsible for more than just mastering or knowing their part. As "specialists," they must also be able to teach it to their fellow teammates. Thus, working together, the group merges the various portions to solve the "puzzle." If carefully structured, the full sequence of a Jigsaw can occur within 50-minutes.

With works of literature having four strong characters such as Antigone (Creon, Antigone, Haemon, Ismene), Hamlet (Gertrude, Claudius, Laertes, Hamlet), or Charlottte's Web (Charlotte, Wilbur, Fern, Templeton), I use a graphic organizer to focus each student's homework assignment and the follow-on class work in the expert teams. For example, with Charlotte's Web, I assign each person in a four-person cooperative learning "home" team one of the characters based on playing card suits. The hearts in each team, for example, focus on Charlotte, the diamonds on Wilbur, the clubs on Fern, and the spades on Templeton.

Each student receives a graphic organizer (see Figure 10.1). As homework, students write in the center block the name of their assigned character. They write on the four spokes the four traits that best describe their character. In the evidence boxes, based on what is known in literature as "close textual reading," they provide support for the traits they chose by citing things the characters do or say, or things that are said about them, giving page numbers for cach example.

FIGURE 10.1

Sample Graphic Organizer

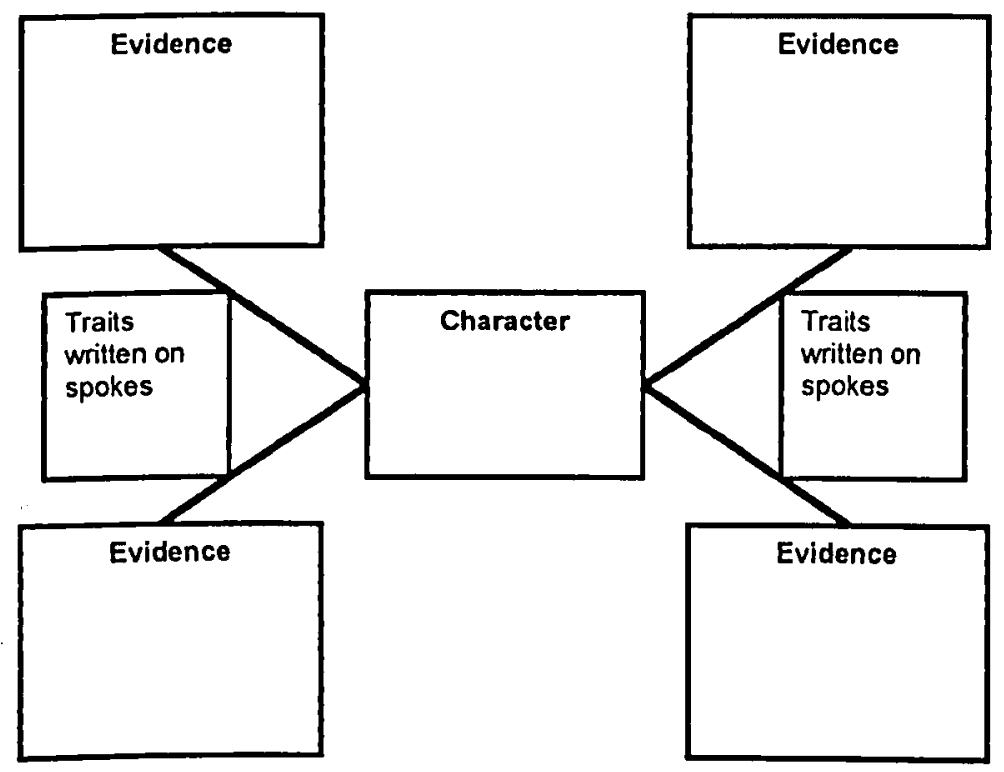


When students come to class with their completed graphic organizers, the hearts from each team assemble in an expert team to review each graphic organizer on Charlotte. They select the four best traits and the best textual evidence to support their decision, creating another graphic organizer synthesizing their ideas. Similarly, expert groups are completing new synthesizing graphic organizers for Wilbur, Fern, and Templeton. The students then return to their home teams, where each in turn teaches their character by sharing their newly created graphic organizer.

Students receive pass-fail points counting toward a criterion-referenced grading scheme for the graphic organizer they brought to class (their homework), but I don't grade their in-class work. I do, however, carefully monitor both expert and home groups to be certain that they remain on task and on target with the content they will share.

The learning that occurs in 50 minutes is enormous. In the expert teams, students are working at the highest levels of Bloom's (1956) taxonomy, evaluating each person's contribution and synthesizing to create a new graphic organizer. In a revised version of Bloom's taxonomy (Anderson \& Krathwohl, 2001), "create" is the highest level of learning. In the home teams, students are teaching other students, a practice research suggests leads to deep learning because it capitalizes on the power of peer tutoring (Fantuzzo, Dimeff, \& Fox, 1989; Fantuzzo, Riggio, Connelly, \& Dimeff, 1989). This in-depth approach to learning can be contrasted with a superficial alternative where a teacher says, "OK class. You have all read Charlotte's Web, so please form groups and discuss the characters."

Jigsaw is remarkably versatile and thus useful even in large classes: The home teams remain the same size, usually composed of four students, but several expert teams can look at the same piece of the puzzle. Three expert teams of four to six students, for example, could look at Charlotte, another three teams could focus on Wilbur, and so on.

Examples of Jigsaw in other disciplines are

- Psychology: Underpinnings of childhood moral development (cognition, social, emotional, biological)

- Botany: The major plant groups (nonvascular land plants; seedless vascular plants; vascular plants with "naked seeds" [gymnosperms]; vascular plants with flowers and protected seeds [angiosperms]

- History: Causes of the American Civil War (economic, political, social)

- Anthropology: Branches of the discipline (cultural, linguistic, physical, - archeology) 
- Biochemistry: Polymers of carbon (carbohydrates, lipids, proteins)

- Accounting: Four methods of depreciation (straight line, units of production, sum of the year's digits, double declining balance)

- Engineering: Designing a solar hot water system (collecting the solar energy, transferring the solar energy to the hot water, storing the hot water, controlling the operation of the system, incorporating safety considerations into the design) (A. Gates, personal communication, August 10, 2005)

- Pharmacy: cholinesterase inhibitors used to treat Alzheimer's (Donepezil, Tacrine, Rivastigmine, Galantamine).

\section{r:Send-a-Problem}

The Send-a-Problem structure gives students the opportunity to identify or focus on their own issues or problems and to participate in a carefully structured problem-solving process in the context of community. Like Jigsaw, if carefully structured, the process can be completed-including reportswithin a 50-minute class period.

To initiate Send-a-Problem, instructors have at hand a list of problems or issues. The instructor can identify the issues, but students have far more investment in the Send-a-Problem activity if they have direct input. I use Send a-Problem in literature classes to pose thought-provoking, open-ended questions. Teams, for example, tackle complex interpretations of characters in a short story such as Theft by Joyce Carol Oates: What do we learn about Marya in the opening pages? What can we deduce about her character/personality? How does Marya feel about herself? How do we know? How are Marya and Imogene Skillman different? In what ways are Marya and Imogene Skillman similar? Explain what kinds of thefts are occurring in the novel.

I bring to class file folders (large envelopes can also be used) with one of the above questions posted on each one. I announce the activity and its time limits. I then distribute the folders, one per team. In large classes, several teams can work simultaneously on the same problems with the caveat that the teams cannot be seated close together. Because of the three steps discussed next, they need to be spaced so that teams have three different problems to address.

The activity proceeds in three carefully structured steps. First, each team discusses its particular problem and generates within the given timeframe as many solutions as possible. The solutions, recorded on a sheet of paper, are placed in the folder. Second, the folders are then passed clockwise to another 
team, which does not open the folder. Reading the problem or issue from the front of the folder, they follow an identical procedure and brainstorm solutions, adding their recorded conclusions to the folder. Third, the folders are passed again, but in this case, the third team opens the folder and reviews the ideas/solutions generated by the other two teams. They can add additional ideas of their own or consolidate those already suggested by the two other teams. Their primary task, however, is to synthesize the best ideas from all three groups in order to reach the most viable conclusion.

Each step is carefully timed. Instructors need to make judgment calls about the total time allotment. Send-a-Problem can be used successfully as a brainstorming activity with each team "blitzing" through as many solutions as possible within a narrow time limit such as four minutes per step. By allotting more time for the discussion and expecting well-crafted mini-essays as responses, I use the structure within a 50-minute class period as a vehicle for meaningful discussion, thoughtful synthesis and evaluation, and creative problem solving. Like Jigsaw, students are working at the highest levels of Bloom's (1956) taxonomy because the final step requires both evaluation and synthesis.

Group reports provide useful closure. If classes are large, precluding a report from every team, two approaches are possible if students have playing cards. In the first case, the teacher draws a card, such as the five of clubs, and asks the person holding it to offer the team's report. The instructor continues drawing cards and hearing reports until class time is over (or until students tire of the responses). Alternatively, the teacher can use a reporting approach called Three Stay, One Stray.

The Three Stay, One Stray structure described by Kagan (1992) requires the easy identification of a team member who will become the group's spokesperson. After the problem-solving discussions are complete, I allow time within the teams for peer coaching so that any team member can give the team's report, an important step to promote accountability. I then call on one of the suits, such as the diamonds, to designate which student from each team will "stray." That is, one student from each group rotates to an adjoining team to give the report. In large classes, the order of rotation must be clear. Playing cards work particularly well because the aces know to rotate to the twos, the jacks to the queens, and so forth.

These designated students, who are welcomed as visitors, share with the new team the results of their original groups' discussion, giving proposed solutions to problems or summarizing discussions.

Three Stay, One Stray offers a low-threat forum where students can exchange ideas and build social skills such as asking probing questions. It also offers students the opportunity to learn by teaching. Placing the report-out 
responsibility on the students reinforces the valuable conception that knowledge resides within the learning community, not just with the "authority figure" instructor. Perhaps its greatest value lies in its efficiency. For example, instead of 10 sequential 5 -minute reports to the entire class (50 minutes, plus transition time), individual students are simultaneously giving 5 -minute reports throughout the room. I usually have the students rotate twice, making two reports, because teams then get exposure to more ideas and the reporter has rehearsal time.

Virtually all disciplines lend themselves to problem-solving activities where many heads are better than one. Here are some examples.

- Medicine: What things would a clinician need to know before considering a diagnosis of Attention-Deficit Disorder/AIDS/Alzheimer's?

- Art: What features would an art historian look for to authenticate an original Rembrandt/Renoir/Klee?

- Religion: Discuss the ramifications and possible solutions for issues facing the Catholic church today (challenges to papal authority, pedophilia, the declining priesthood, etc.).

- History: Outline the various claims to territory of the cattleman, the farmers, and the Native Americans.

- Geography: Explain the effects of linguistic diversity on European unity. What makes the Balkan region unique as compared to other shatter belts? Discuss the relationship between the pattern of landforms and cultural diversity in Eastern Europe (K. Hart, personal communication, July 30, 1999).

The Send-a-Problem concept does not need to be limited to issues only. In place of the folders, geologists can pass around rocks needing identification, paralegal instructors can have teams fill out worksheets on various legal books, and ESL or language teachers can have teams caption various cartoons using the target language.

\section{-Cooperative Debates}

In my English literature class studying Antigone, I establish teams of four to five students to examine two key questions relevant to the play: Pro/Con: Should Antigone have buried her brother? and Pro/Con: Should Creon be impeached for poor leadership?

Students draw slips of paper to determine their teams. This random approach allows students to interact with a variety of classmates and ensures 
that the highest achieving students do not self-select each other, thus skewing the debate results.

As homework, each student reads the play closely and gathers support for their team's perspective. I give students class time to compare their notes and work on preparing the best possible arguments. I expect students to contribute evidence from the play based on their close textual reading as well as any other insights into the issues, such as concepts gleaned from class discussions and from an earlier guest lecturer speaking on justice and legality.

I carefully explain the ground rules to the students. Because I want all the team members to be prepared to debate and to understand the material well enough to present their side, I determine each team's spokesperson at random just before the debate begins. Thus, the teams are potentially only as strong as their weakest member, a situation that results in a lot of peer coaching and genuine learning. The spokespersons have four minutes to present their sides. I then allow each team four minutes to prepare a rebuttal. In the second round, the teams choose their own spokesperson. The rebuttals last three minutes. Then, the students who are observing the debate (the half of the class assigned to the other debate topic) vote to determine which side has made the most convincing argument. The second pair of teams then follow the same procedure for their debate on the second question.

The 50-minute class period provides a perfect setting for these highly animated, hotly contested cooperative debates. Best of all, students clearly do their homework, coming to class with an in-depth knowledge of the literary work and the issues surrounding both these questions.

Almost all disciplines have key issues that lend themselves well to debate.

- Computer science: Blackboard or WebCT platforms?

- History: Should the US have dropped the second bomb on Nagasaki?

- Biology: To clone or not to clone?

- Economics: Should the US adopt a flat rate income tax system?

\section{Guided Reciprocal Peer Questioning}

Developed and researched by King $(1990,1992,1995)$, this activity helps students to generate task-specific questions that can then be answered within a cooperative team. Guided Reciprocal Peer Questioning empowers students to take charge of their own learning - to generate their own critical questionsthrough structured practice. 
To initiate this activity, I give each student a copy of King's question stems (see Appendix 10.1) and ask them to email me three to five authentic questions (ones they truly want to discuss) on a given work of literature such as Gwendolyn Brooks's Maud Martha. These question stems, based on Bloom's (1956) taxonomy, challenge students to move beyond dualistic thinking by forming questions such as "What are the strengths and weaknesses of ...?" I provide specific examples to help students understand the process of generating effective questions.

Students bring their questions to class and use them in their cooperative teams. I assign four roles through the playing cards in each group: discussion leader, recorder, reporter, and time keeper. The team leader poses one of the specific questions he or she has written to which the other team members respond. Since the questions do not have a single right answer, reflective discussion follows. Each student in turn offers a question for the team to discuss, preferably using a different stem. The recorders in each team capture the question posed and the gist of the discussion. About 20 minutes before the close of class, I ask the teams to review their recorders' notes and to determine the question-and the subsequent discussion-that led to the most productive insights. Because my writing-based literature classes are typically small, I ask each team (usually four to five teams composed of four students each) to succinctly share their best question and discussion. In larger classes, instructors might want to share a few randomly selected reports, but then have all of them emailed for later posting to a web page or for distribution to students through email or course management systems such as WebCT or Blackboard.

This activity lends itself to virtually any discipline. The possibilities are seemingly endless. King (1995) notes that she and her colleagues throughout California have used the question stems with subjects as diverse as anthropology, biology, business accounting, history, mathematics, psychology, research methods, and teacher education. The more often students practice this activity, the higher the quality of the questions, particularly if the instructor has conscientiously provided feedback on the quality of the questions, reinforcing those that promote higher order thinking. Davis (1993) reminds us that

[Good thinking] is learned by practice-by thinking-under the guidance and criticism of an effective mentor, presumably a teacher who is also a "good thinker" and who understands thinking processes. Above all, thinking involves asking questions-sometimes new questions about old questions in the search for new answers. (p. 234) 


\section{Bingo}

Bingo offers a game format easy to adapt to many teaching needs. Bingo sheets can be created using the "Table" option on most word processing packages. Alternatively, Sugar (1998), of the Game Group, has developed a set of reusable materials for a variation of Bingo called QUIZO. Bingo, often classified as a "frame game" or a "matrix game" is easily adapted to virtually any teaching scenario. When carefully structured and paced, the game can be played successfully in 50-minute class periods.

I use Bingo to get students to review material for the midterm or final examination. I coach them on designing and submitting appropriate questions, an ongoing process throughout the semester or half semester.

Most students need to be coached on question writing. Learning to pose viable, cogent questions is a valuable skill. For example, a Nobel prize-winning physicist, Isidor Rabi, credits his mother with prompting him to value the questions he asked above the answers he gave. When he returned from school, she would never ask him what he learned that day. Instead, she would ask, "What good questions did you ask today?" (Barell, 1988, qtd. in Costa \& O'Leary, 1992, p. 59). Students tend to make their questions too rigid for the Bingo format. They need to allow for some wiggle room (e.g., not, "Name the characters in Ernest Gaines's A Lesson Before Dying," but "Name three important characters in A Lesson Before Dying").

I have students submit two types of questions: factual ones, that I can use to speed up play, and open-ended ones, which result in in-depth learning. The student who submits the question becomes the "arbitrator" of acceptable answers, not me. Thus, students post questions to a web page in the following format:

\section{Type of Question: Factual}

\begin{tabular}{ll}
\hline The Question: & Define plagiarism \\
Student's Name: & John Doe \\
The Answer: & $\begin{array}{l}\text { To steal or pass off the words or ideas of another as one's own, without } \\
\text { crediting the source. }\end{array}$ \\
& Student Handbook, p. 77. \\
\hline
\end{tabular}

I carefully review all the questions, returning for revision any that are inappropriate. Before the game, I add any significant questions that will help students learn critical material. I then rank order the questions within the two 
categories (factual and open-ended) so that the most valuable questions will occur early in the play.

To use the questions during play, I enlarge the fonts to prepare transparencies or to project slides. At the top appears the question and the person submitting it. Space between the student's name and the answer that follows it allows the answer to be easily covered or added later in a PowerPoint slide.

I purchase needed supplies: Skittles or M\&Ms for the markers (seasonal markers can be candy corn or Valentine hearts), and candy bars-large and snack sizes-for the prizes (healthier prize alternatives are bags of pretzels, cocoa packets, ballpoint pens, etc.).

To play the game, I pair students, forming a trio if there are an uneven number of participants. Although most students know the object of Bingo (five markers in a row in any direction) and the rules of play, it is important to explain the procedures so that anyone unfamiliar with Bingo will not feel compromised or inept. Each pair receives markers and two-colored worksheets (as an example, green for the factual; gold for the higher-level openended questions) where they record their answers and if they were right or wrong. They can also note the space where the marker is to go. A worksheet, which is abbreviated here, looks like this:

\section{Factual Questions}

Pair or trio (responding to a question about William Faulkner's $A$ Rose for Emily):

\begin{tabular}{lccr} 
& Answer & $\begin{array}{l}\text { Right or } \\
\text { Wrong? }\end{array}$ & Space \\
\hline 1) rat poison & Right & B2 \\
2) & & \\
\hline
\end{tabular}

The teacher then poses the questions in sequence within each category, giving sufficient time based on their complexity. To make the game participant-centered and to allow students to receive feedback on the viability and fairness of their questions, I have the student who submitted the question call "time" and then decide what alternative answers are acceptable.

Pairs with correct answers place a marker on the designated square (e.g., $\mathrm{B} 3$ or $\mathrm{Gl}$ ). The square is determined by having the pairs in turn draw a Scrabble tile or a homemade variation $(B, I, N, G, O)$ and roll a die (they roll again if a six emerges or teachers can purchase ten-sided die with only five numbers at novelty shops). 
Pacing is very important in a 50-minute class period. The factual questions speed up play and the higher-order thinking questions, as indicated earlier, lead to valuable discussions. I can typically ask 25 factual questions and 12 open-ended ones, but the number will depend on the depth of the openended responses and the skill of the student "arbiters." Thus, always mindful of the clock, a savvy Bingo facilitator will offer frequent open-ended questions for their learning value but speed up play with factual questions. To facilitate this process, I have the stacks of sorted transparencies on either side of an overhead projector. Teachers comfortable with computer projections can toggle between the two types of questions.

The first pair (often there will be ties) to cover five contiguous squares in any direction declares "Bingo." After the two (or sometimes three) students select a prize, they then clear their board and continue playing until the time period ends. In a 50-minute class period, it is theoretically possible for every pair to become "winners."

There are many reasons to use a Bingo game format. Because students submit in advance questions for which they are responsible, they are far more likely to read and reflect on the desired material. Furthermore, the very process of framing questions and later receiving feedback on their value, efficacy, and fairness encourages students to concentrate on learning useful information and skills. Bingo also has assessment value: The worksheets completed by student pairs during play offer teachers valuable insights into what students know and don't know. They also uncover important misconceptions that might be addressed on other occasions.

Useful in virtually any discipline, Bingo games keep students actively engaged with the material, thus increasing the likelihood of their remembering it. As Rodgers and Starrett (2005) state, "If we as educators can find a way to tap into the power of games to deeply engage students, we will have found a truly exciting tool for teaching and learning" (p. 11). Enthusiastic and energetic, students often high-five each other when they get a correct answer. They listen attentively to the answers and suddenly care about the material. Best of all, Bingo games build collegiality. The pairs who work together develop personal bonds and the whole-group discussions over the open-ended questions allow students to engage in meaningful conversations that would likely not occur in less structured settings. 


\section{Conclusion}

Good teaching, as faculty developers know, is not simply a grab bag of techniques. One of our key responsibilities is helping faculty to appreciate and capitalize on the complexity and richness of teaching and learning, particularly within a learning-centered context. One way to do this is to frame specific techniques such as the ones discussed here-Jigsaw, Send-a-Problem, Cooperative Debates, Guided Reciprocal Peer Questioning, and Bingowithin the context of sequencing activities with an emphasis on cooperative learning during face-to-face class time, even in brief 50-minute periods.

\section{References}

Anderson, L. W., \& Krathwohl, D. R. (Eds.). (2001). A taxonomy for learning, teaching, and assessing: A revision of Bloom's taxonomy of educational objectives. New York, NY: Longman.

Barr, R. B., \& Tagg, J. (1995, November/December). From teaching to learning-A new paradigm for undergraduate education. Change, 27(6), 12-25.

Bloom, B. S. (Ed.). (1956). Taxonomy of educational objectives: Handbook 1. Cognitive domain. New York, NY: Longman.

Bransford, J. D., Brown, A. L., \& Cocking, R. R. (Eds.). (2000). How people learn: Brain, mind, experience, and school (Expanded ed.). Washington, DC: National Academies Press.

Costa, A. L., \& O'Leary, P. W. (1992). Co-cognition: The cooperative development of the intellect. In J. Davidson \& T. Worsham (Eds.), Enhancing thinking through cooperative learning (pp. 41-65). New York, NY: Teachers College Press.

Davis, J. R. (1993). Better teaching, more learning: Strategies for success in postsecondary settings. Phoenix, AZ: American Council on Education/Oryx Press.

Fantuzzo, J. W., Dimeff, L. A., \& Fox, S. L. (1989). Reciprocal peer tutoring: A multimodal assessment of effectiveness with college students. Teaching of Psychology, 16(3), 133-135.

Fantuzzo, J. W., Riggio, R. E., Connelly, S., \& Dimeff, L. A. (1989). Effects of reciprocal peer tutoring on academic achievement and psychological adjustment: $A$ component analysis. Journal of Educational Psychology, 81(2), 173-177.

Feichtner, S. B., \& Davis, E. A. (1984-85). Why some groups fail: A survey of students' experiences with learning groups. Organizational Behavior Tenching Review, 9(4), 58-71. 
Felder, R. M., \& Brent, R. (1994). Cooperative learning in technical courses: Procedures, pitfalls, and payoffs. Retrieved June 16, 2006, from the North Carolina State University web site: www.ncsu.edu/felder-public/Papers/Coopreport.html\#Issues AndAnswers

Fink, L. D. (2003). Creating significant learning experiences: An integrated approach to designing college courses. San Francisco, CA: Jossey-Bass.

Finkel, D. L. (2000). Teaching with your mouth shut. Portsmouth, NH: Boynton/Cook.

Kagan, S. (1992). Cooperative learning. San Juan Capistrano, CA: Kagan Cooperative Learning.

King, A. (1989, October). Effects of self-questioning training on college students' comprehension of lectures. Contemporary Educational Psychology, 14(4), 366-381.

King, A. (1990, Winter). Enhancing peer interaction and learning in the classroom through reciprocal questioning. American Educational Research Journal, 27(4), 664-687.

King, A. (1992). Promoting active learning and collaborative learning in business administration classes. In T. J. Frecka (Ed.), Critical thinking, interactive learning, and technology: Reaching for excellence in business education (pp. 158-173). Chicago, IL: Arthur Andersen Foundation.

King, A. (1994). Autonomy and question asking: The role of personal control in guided student-generated questioning. Learning and Individual Differences, 6(2), 162-185.

King, A. (1995, Winter). Guided peer questioning: A cooperative learning approach to critical thinking. Cooperative learning and college teaching, 5(2), 15-19.

Lyman, F. (1981). The responsive classroom discussion: The inclusion of all students. In A.S. Anderson (Ed.), Mainstreaming digest (pp. 109-113). College Park, MD: College of Education, University of Maryland.

Millis, B. J. (1994). Conducting cooperative cases. In E. C. Wadsworth (Ed.), To improve the academy: Vol. 13. Resources for faculty, instructional, and organizational development (pp. 309-328). Stillwater, OK: New Forums Press.

Millis, B. J. (2002). Enhancing learning-and more!-through cooperative learning (IDEA Paper No. 38). Retrieved June 16, 2006, from the Kansas State University, IDEA Center web site: www.idea.ksu.edu/papers/Idea_Paper_38.pdf

Millis, B. J., \& Cottell, P. G., Jr. (1998). Cooperative lcarning for higher education faculty. Phoenix, AZ: American Council on Education/Oryx Press. 
Rodgers, M. L., \& Starrett, D. A. (2005, October). Is it time to get in the game? National Teaching \& Learning Forum, 14(6), 10-11.

Stein, R. F., \& Hurd, S. (2000). Using student teams in the classroom: A faculty guide. Bolton, MA: Anker.

Streuling, G. F. (2004). Overcoming initial mistakes when using small groups. In L. K. Michaelsen, A. B. Knight, \& L. D. Fink (Eds.), Team-based learning: A transformative use of small groups in college teaching (pp. 133-143). Sterling, VA: Stylus.

Sugar, S. (1998). Games that teach: Experiential activities for reinforcing learning. San Francisco, CA: Pfeiffer.

Tuckman, B. W. (1965). Developmental sequence in small groups. Psychological Bulletin, 63(6), 384-399.

Tuckman, B. W., \& Jensen, M. A. C. (1977). Stages of small-group development revisited. Group and Organizational Studies, 2(4), 419-427.

Weimer, M. (2002). Learner-centered teaching: Five key changes to practice. San Francisco, CA: Jossey-Bass. 
Appendix 10.1

Guiding Critical Thinking

\begin{tabular}{|c|c|}
\hline Generic Questions & $\begin{array}{l}\text { Specific Thinking } \\
\text { Processes Induced } \\
\end{array}$ \\
\hline Explain why __. (Explain how __..) & analysis \\
\hline What would happen if ___ ? & prediction/hypothesizing \\
\hline What is the nature of ___ ? & analysis \\
\hline What are the strengths and weaknesses of ___ ? & analysis/inferencing \\
\hline What is the difference between __ and _ ? & comparison-contrast \\
\hline Why is ___ happening? & analysis/inferencing \\
\hline What is a new example of ___ ? & application \\
\hline How could ___ be used to ___ & application \\
\hline What are the implications of ___? & analysis/inferencing \\
\hline What is__ analogous to? & $\begin{array}{l}\text { identification/creation of } \\
\text { analogies and metaphors }\end{array}$ \\
\hline How does___effect ___? & $\begin{array}{l}\text { analysis of relationship } \\
\text { (cause-effect) }\end{array}$ \\
\hline How does _ tie in with what we learned before? & activation of prior knowledge \\
\hline Why is __ important? & analysis of significance \\
\hline How are ___ and ___ similar? & comparison-contrast \\
\hline How does___ apply to everyday life? & application - to the real world \\
\hline What is a counterargument for & rebultal to argument \\
\hline What is the best__, and why? & $\begin{array}{l}\text { evaluation and provision of } \\
\text { evidence }\end{array}$ \\
\hline What is the solution to the problem of ___ ? & synthesis of ideas \\
\hline Compare ___ and ___ with regard to. & $\begin{array}{l}\text { comparison-contrast and } \\
\text { evaluation based on criteria }\end{array}$ \\
\hline What do you think causes___ Why? & $\begin{array}{l}\text { analysis of relationship } \\
\text { (cause-effect) }\end{array}$ \\
\hline
\end{tabular}


Do you agree or disagree with this statement:

What evidence is there to support your answer?

What is another way to look at ?

What does mean?

Describe in your own words.

Summarize in your own words.

Note. Adapted from King (1989, 1992, \& 1994). evaluation and provision of evidence taking other perspectives comprehension comprehension comprehension 